\title{
Further Evidence That Stress Hyperthermia is a Fever ${ }^{1}$
}

\author{
MATTHEW J. KLUGER, BARBARA O'REILLY, TIMOTHY R. SHOPE \\ AND ARTHUR J. VANDER \\ Department of Physiology, The University of Michigan Medical School, Ann Arbor, MI 48109
}

Received 20 November 1986

\begin{abstract}
KLUGER, M. J., B. O'REILLY, T. R. SHOPE AND A. J. VANDER. Further evidence that stress hyperthermia is a fever. PHYSIOL BEHAV 39(6) 763-766, 1987.-Exposure of rats to an open-field results in a rapid rise in body temperature. Fifty-four percent of this rise in body temperature was blocked by intracerebroventricular administration of the antipyretic drug sodium salicylate. Intraperitoneal administration of indomethacin, a potent blocker of prostaglandin production, also attenuated the stress-induced hyperthermia to the same degree. Based on the data presented in this and an earlier study, we conclude that a major component of the rise in body temperature induced by psychological stress in rats is mediated by prostaglandins released by the central nervous system, and may therefore be a fever.
\end{abstract}

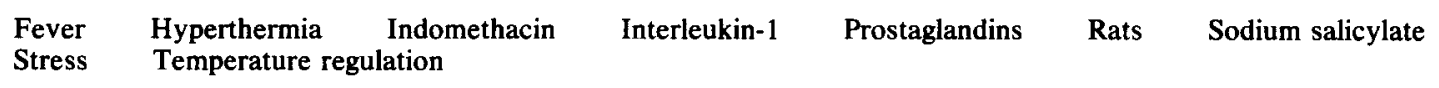

PSYCHOLOGICAL stress has been shown to result in an acute rise in body temperature in rats $[3-5,10,11,16,18,20$, $22]$, rabbits $[17,21]$, and people $[12,15]$. Briese and Cabanac [5] and we [16] have shown that much of the rise in temperature caused by exposure to a novel environment can be blocked by pre-treatment with an intraperitoneal injection of an antipyretic dose of sodium salicylate. Based on this finding and the fact that antipyretic drugs are thought to exert their action by inhibiting the formation of prostaglandins (of the $E$ series) [19], we hypothesized that most of the rise in body temperature associated with psychological stress is mediated by the release of prostaglandins in areas of the central nervous system responsible for regulating body temperature and may be a true fever (i.e., a rise in the thermoregulatory "set-point").

If this is the case, then antipyretic drugs injected directly into the lateral cerebral ventricles might also be expected to attenuate this rise in body temperature (e.g., see [7]). In the present study we have tested this hypothesis and found that injection of sodium salicylate directly into the central nervous system attenuates stress hyperthermia. In addition, this study demonstrates that another antipyretic drug, indomethacin (a more potent prostaglandin blocker), also attenuates stress-induced hyperthermia.

\section{METHOD}

\section{Animals}

Specific pathogen-free male Sprague-Dawley rats weighing 200 to $300 \mathrm{~g}$ were obtained from Charles River Breeding Laboratories, Inc., Portage, MI. Rats were housed in indi- vidual plastic cages in a room maintained at $26 \pm 1^{\circ} \mathrm{C}$, i.e., in the thermoneutral zone for rats, with a photoperiod consisting of $12 \mathrm{hr}$ of light and $12 \mathrm{hr}$ of dark. Tap water and rodent chow (Purina) were provided ad lib.

\section{Measurement of Body Temperature}

Body temperature was measured using battery-operated biotelemetry devices (Mini-Mitter, Inc., Sunriver, OR) implanted intraperitoneally into each rat four or more days before the stress experiments began. Each transmitter was calibrated prior to implantation. Output (frequency in $\mathrm{Hz}$ ) was monitored by a mounted antenna placed under each animal's cage and fed into a peripheral processor (Dataquest III Systems, Mini-Mitter, Inc.) connected to an IBM-PC. Temperatures were generally monitored and recorded at 5 minute intervals. Prior to any experimental manipulation, basal temperatures were recorded for at least 60 minutes.

\section{Cannulation of Lateral Cerebral Ventricles}

Rats were anesthetized by IM injection of ketamine hydrochloride $(87 \mathrm{mg} / \mathrm{kg})$ and xylazine hydrochloride $(12.9$ $\mathrm{mg} / \mathrm{kg}$ ) and placed in a Kopf stereotaxic apparatus. A $1.5 \mathrm{~cm}$ incision was made in the midline of the cranium and the skull visualized. A stainless steel cannula (No. 220, David Kopf, Tununga, CA) to serve as a guide-tube was placed in the right lateral cerebral ventricle as described by Bailey et al. [1]. At least one week was allowed for recovery before the rats were used in an experiment. In the experiment, a 27 gauge needle with tubing attached to its distal end was inserted into the cannula until the resistance of the protective

\footnotetext{
${ }^{1}$ Research sponsored by ONR contract N00014-K-0027 and NIH grant A01-NS23633.
} 


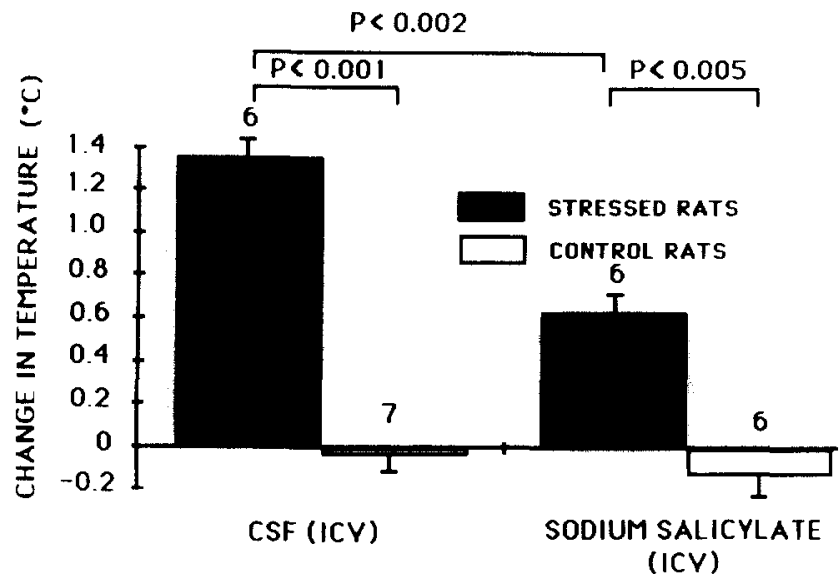

FIG. 1. Effects of sodium salicylate $(1 \mathrm{mg} / \mathrm{kg}$ ) or vehicle (artificial CSF) injected into a lateral cerebral ventricle on deep body temperature (mean \pm 1 S.E.) in stressed and control (unstressed) rats. Stressed rats were exposed to an "open-field" for 30 minutes, whereas control rats were left in their cages for this period. The changes in temperature are for the period immediately prior to and after the open-field exposure (or the equivalent period for the control rats). Numbers above each bar denote sample sizes.

rubber diaphragm at the base of the cannula was encountered; the needle was then pushed forward gently through the diaphragm and the fluid (see below) injected over several seconds. The entire procedure took approximately 30 seconds; during it the rat was held loosely with one finger on its head just above the eyes. The rats had been conditioned to this holding daily for at least three or four days; no struggling or squealing occurred. Further evidence that the injection procedure itself was not stressful is that any stress hyperthermia elicited by it was of less than $0.2^{\circ} \mathrm{C}$ and 15 minutes duration.

\section{Stress Paradigm}

Acute psychological stress in rats can be induced by exposure to an open-field $[6,16]$. The open-field used in these experiments consisted of a $60^{\prime \prime} \times 38^{\prime \prime} \times 81^{\prime \prime}$ high white acrylic spray finish temperature controlled chamber (Warren Sherer) illuminated by both fluorescent lights and a $200 \mathrm{~W}$ white light suspended from above. The temperature within the open-field box was the same as that in the rats' home cages, $26^{\circ} \mathrm{C}$. The experimental protocol for the stress in volved transporting each rat from the home room to the stress room, removing the rat from the cage and placing him into the open-field box. After 30 minutes, the rat was returned to his cage and taken back to the housing area. Care was taken not to disturb the rats either before or after the stress-exposure. Control animals were not placed in the open-field box. All animals were conditioned to handling for at least 3 days prior to the experiments. To minimize possible circadian variability, all exposure to the open-field occurred between 9 a.m. and 2 p.m.

\section{Experiment 1: Effect of Intracerebroventricular (ICV) Injection of Sodium Salicylate on Stress-Induced Hyperthermia}

Thirteen rats received $20 \mu \mathrm{l}$ (ICV) of artificial cerebrospinal fluid (CSF) and twelve received $20 \mu$ l (ICV) of CSF in

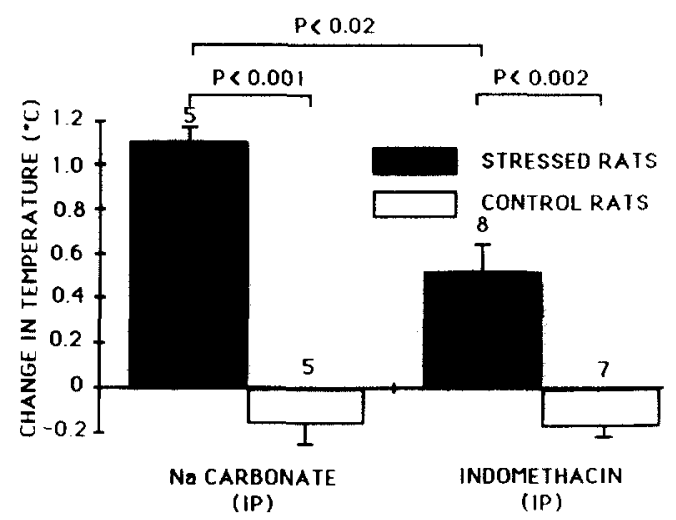

FIG. 2. Effects of indomethacin ( $10 \mathrm{mg} / \mathrm{kg}$ intraperitoneally) or vehicle (sodium carbonate) on deep body temperature (mean \pm 1 S.E.) in stressed and control (unstressed) rats. Stressed rats were exposed to an "open-field" for $\mathbf{3 0}$ minutes, whereas control rats were left in their cages for this period. The changes in temperature are for the period immediately prior to and after the open-field exposure (or the equivalent period for the control rats). Numbers above each bar denote sample sizes.

which was dissolved sodium salicylate to provide a dose of 1 $\mathrm{mg}$ sodium salicylate per $\mathrm{kg}$ body weight. All injections were immediately followed by a $30 \mu 1$ flush with CSF. Sixty minutes later, six rats from each group were exposed to openfield stress and the others remained in their home cages and served as non-stressed controls.

\section{Experiment 2: Effect of Intraperitoneal Injection of Indomethacin on Stress-Induced Hyperthermia}

Ten rats received intraperitoneal (IP) injections of 0.7 to $1.0 \mathrm{ml}$ sterile sodium carbonate $\left(1.1 \times 10^{-3} \mathrm{M}\right)$, and fifteen rats were injected IP with 0.7 to $1.0 \mathrm{ml}$ of $10 \mathrm{mg} / \mathrm{kg}$ indomethacin (Merck, Sharp \& Dohme) dissolved in the sodium carbonate. Five hours later five of the sodium carbonate-injected rats and eight of the indomethacininjected rats were exposed to open-field and the others remained in their home cages and served as non-stressed controls.

\section{Data Analysis}

Values reported are mean \pm 1 S.E. Comparisons between each experimental and control group were analyzed for statistical significance using the Student's $t$-test. Comparisons among groups were made using one-way ANOVA, followed by Scheffe allowances for multiple comparisons among means.

\section{RESULTS}

Experiment 1: Effect of Intracerebroventricular (ICV) Injection of Sodium Salicylate on Stress-Induced Hyperthermia

The change in body temperature due to the stress period, calculated by subtracting the pre-stress temperature (temperature immediately prior to removing each rat from its home cage) from the post-stress temperature (temperature immediately after returning the rat from the open-field to its 
home cage) is shown in Fig. 1. Following the $\mathbf{3 0}$ minute stress period, the rise in body temperature of the rats injected ICV with artificial CSF was $1.36 \pm 0.10^{\circ} \mathrm{C}$, significantly different $(p<0.001)$ from the change in body temperature of the nonstressed control rats injected with artificial CSF and maintained in their home cages. Stressed rats injected ICV with sodium salicylate $(1 \mathrm{mg} / \mathrm{kg})$ also had a rise in body temperature, $0.63 \pm 0.11^{\circ} \mathrm{C}$, significantly different from the nonstressed control rats that were injected with sodium salicylate $(p<0.005)$. However, the rise in body temperature of stressed rats injected with sodium salicylate was significantly less $(p<0.002)$ than the rise seen in stressed rats injected with artificial CSF; the mean difference between these groups $\left(0.73^{\circ} \mathrm{C}\right)$ amounted to $54 \%$. Activity of the animals in the open-field box was not quantified, but no difference between the controls and drug-treated animals was apparent from simple observation. Most animals of both groups went into a corner of the box and remained there.

\section{Experiment 2: Effect of Intraperitoneal Injection of Indomethacin on Stress-Induced Hyperthermia}

Following the 30 minute stress period, the rise in body temperature of the rats injected IP with sodium carbonate was $1.11 \pm 0.09^{\circ} \mathrm{C}$, significantly different from the change in body temperature of the non-stressed control rats injected with sodium carbonate and maintained in their home cages $(p<0.001)$ (Fig. 2). Stressed rats injected with indomethacin $(10 \mathrm{mg} / \mathrm{kg})$ also had a rise in body temperature, $0.52 \pm 0.19^{\circ} \mathrm{C}$, significantly different from that in control rats that were injected with sodium carbonate $(p<0.002)$. However, the rise in body temperature of rats injected with indomethacin was significantly less $(p<0.02)$ than that seen in rats injected with sodium carbonate; the mean difference between these two groups $\left(0.59^{\circ} \mathrm{C}\right)$ amounted to $53 \%$. As in Experiment 1 , no difference in activity between the controls and drug-treated animals was apparent from simple observation.

\section{DISCUSSION}

This study further supports the hypothesis [16] that a major component of the hyperthermia that occurs during exposure of rats to an open-field (presumably a psychological stress) is mediated by prostaglandins released by the central nervous system: (1) The central administration (intracerebroventricular injection) of salicylate blocked $54 \%$ of the rise seen in the controls, similar to the $69 \%$ attenuation reported for systemic (intraperitoneal) salicylate administration; (2) a second inhibitor of prostaglandin synthesis, indomethacin, exerted an attenuating effect on the temperature rise identical to that of salicylate.

Since part of the elevated thermoregulatory set-point during fever is attributed to an increase in prostaglandin concentration in the central nervous system [19], our findings raise the possibility that the hyperthermia of open-field psychological stress is, at least in part, a fever. During infection, the sequence of events leading to fever is thought to be initiated by the synthesis and release of interleukin-1 (IL-1; formerly called "endogenous pyrogen") from activated macrophages and other phagocytic cells $[8,13]$. IL-1 has been shown to stimulate an elevation in prostaglandin concentrations in many tissues, including the central nervous system [2] and cultured hypothalamic cells [14]. Within the past few years, several laboratories have shown that IL-1 can, itself, be produced by cells within the central nervous system (e.g., [9]). It is possible, therefore, that exposure of rats to an open-field results in an acute release of IL-1, which induces fever in these rats by elevating central nervous system concentrations of prostaglandins.

Were psychological stress to result in the acute release of IL-1, then it is possible that other "acute-phase responses" mediated by IL-1 $[8,13]$ may also be initiated. Whether these other IL-1-mediated effects occur in response to psychological stress would depend, of course, on the cell population(s) responsible for the release of the IL-1.

Finally, it should be emphasized that although the antipyretic drugs greatly attenuated the hyperthermia induced by open-field stress, they did not completely eliminate it. The nature of this other component of the hyperthermia was not investigated in the present study.

\section{REFERENCES}

1. Bailey, P. T., F. B. Abeles, E. C. Hauer and C. A. Mapes. Intracerebroventricular administration of leukocytic endogenous mediators in the rat. Proc Soc Exp Biol Med 153: 419-423, 1976.

2. Bernheim, H. A., T. M. Gilbert and J. T. Stitt. Prostaglandin E levels in the third ventricular cerebrospinal fluid of rabbits during fever and change in body temperature. J Physiol 301: 69-78, 1980.

3. Blasig, J., V. Hollt, U. Bauerle and A. Herz. Involvement of endorphins in emotional hyperthermia of rats. Life Sci 23: 2525-2532, 1978.

4. Briese, E. and M. G. De Quijada. Colonic temperature of rats during handling. Acta Physiol Latinoam 20: 97-102, 1970.

5. Briese, E. and M. Cabanac. Emotional fever and salicylate. Proc of 28th Intern Cong Physiol Sci, 1980, pp. 161-163.

6. Clamage, D. M., C. S. Sanford, A. J. Vander and D. R. Mouw. Effects of psychosocial stimuli on plasma renin activity in rats. Am J Physiol 231: 1290-1294, 1976.

7. Clark, W. G. and Y. L. Clark. Changes in body temperature after administration of antipyretics, LSD, THC CNS depressants and stimulants, hormones, inorganic ions, gases, 2,4DNP and miscellaneous agents. Neurosci Biobehav Rev 5: 1-136, 1981.

8. Dinarello, C. A. Interleukin-1. Rev Infect Dis 6: 51-95, 1984.
9. Fontana, A., E. Weber and J.-M. Dayer. Synthesis of interleukin-1/endogenous pyrogen in the brain of endotoxintreated mice: a step in fever induction? $J$ Immunol 133: 1696$1698,1984$.

10. Goldstein, A. and P. Lowery. Effect of the opiate antagonist naloxone on body temperature in rats. Life Sci 17: 927-932, 1975.

11. Gollnick, P. D. and C. D. Ianuzzo. Colonic temperature response of rats during exercise. J Appl Physiol 24: 747-750, 1968.

12. Hasan, M. K. and A. C. White. Psychogenic fever: entity or nonentity. Postgrad Med 66: 152-154, 1979.

13. Kluger, M. J., J. J. Oppenheim and M. C. Powanda (Editors). The physiologic, metabolic and immunologic actions of interleukin-1. Proceedings of the International Symposium held in Ann Arbor, MI, June 4-6, 1985. In: Progress in Leukocyte Biology. New York: Alan R. Liss, 1985.

14. Mier, J. W., L. M. Souza, M. Allegretta, T. Boone, H. A. Bernheim and C. A. Dinarello. Dissimilarities between human interleukin-1 and recombinant human interleukin-2 in the induction of fever, brain prostaglandin, and acute phase protein synthesis. J Biol Response Mod 4: 35-45, 1985. 
15. Renbourn, E. T. Body temperature and pulse rate in boys and young men prior to sporting contests. A study in emotional hyperthermia: with a review of the literature. J Psychosom Res 4: $149-175,1960$.

16. Singer, R., C. T. Harker, A. J. Vander and M. J. Kluger. Hyperthermia induced by open-field stress is blocked by salicylate. Physiol Behav 36: 1179-1182, 1986.

17. Snow, A. E. and A. Horita. Interaction of apomorphine and stressors in the production of hyperthermia in the rabbit. $J$ Pharmacol Exp Ther 220: 335-339, 1982.

18. Stewart, J. and R. Eikelboom. Stress masks the hypothermic effect of naloxone in rats. Life Sci 25: 1165-1172, 1979.
19. Stitt, J. T. Prostaglandin E as the neural mediator of the febrile response. Yale J Biol Med 59: 137-149, 1986.

20. Vidal, C., C. Sauaudeau and J. Jacob. Hyper- and hypothermia induced by non-noxious stress: effects of naloxone, diazepam and gamma-acetylenic GABA. Life Sci 33: 587-590, 1983.

21. Yokoi, Y. Effect of ambient temperature upon emotional hyperthermia and hypothermia in rabbits. I Appl Phwsiol 21: 1795$1798,1966$.

22. York, J. L. and S. G. Regan. Conditioned and unconditioned influences on body temperature and ethanol hypothermia in laboratory rats. Pharmacol Biochem Behav 17: 119-124, 1982. 